\title{
Ovarian Reserve Assessed by the Anti-Mullerian Hormone and Reproductive Health Parameters in Women With Crohn'S Disease, a Case-Control Study
}

\author{
Tomáš KOLLER ${ }^{1}$, Jana KOLLEROVÁ ${ }^{1}$, Tibor HLAVATÝ ${ }^{1}$, Barbora KADLEČKOVÁ ${ }^{2}$, \\ Juraj PAYER ${ }^{1}$
}

${ }^{1} 5^{\text {th }}$ Department of Internal Medicine, Comenius University Faculty of Medicine, University Hospital Bratislava, Bratislava, Slovakia, ${ }^{2}$ Gastroenterological Centre ASSIDUO, Bratislava, Slovakia

Received April 25, 2021

Accepted August 18, 2021

\section{Summary}

According to several studies, women with Crohn's disease (CD) had reduced fertility, which is mostly due to voluntary decisions and reduced ovarian reserve. In our study, we aimed to compare reproductive health parameters (RHP), previous pregnancy complications and outcomes, and ovarian reserve (OR) assessed by the anti-Mullerian hormone (AMH) in $\mathrm{CD}$ patients with healthy controls. In $C D$ patients, we also compared $O R$ according to disease phenotypes. Consecutive pre-menopausal women with CD from two IBD centers were included. The control group consisted of age and BMI-matched healthy controls. We used a questionnaire that included RHP, CD phenotype, and $C D$ activity. Serum AMH was assessed by the Elecsys AMH plus essay. We enrolled 50 patients and 56 controls with a median age of 31 years. All CD patients were in clinical remission. We observed no difference in RHP or AMH (median 2.6 vs. $2.1 \mathrm{ug} / \mathrm{l}$, $\mathrm{p}=0.98)$, or the proportion of low $\mathrm{OR}(\mathrm{AMH}<1,77,38$ vs. $41.1 \%, p=0.84)$. The slope of age-related decrease did not differ between the groups. The subgroup of $C D$ patients after surgery and those older than 30 years with $C D$ for $>5$ years had a steeper decrease in AMH (slope -0.12 vs. $-0.29, p=0.04$ and 0.31 vs. $-0.2, p=0.029$ ). In a multivariate analysis, age was the single independent predictor of low $\mathrm{OR}(\mathrm{OR}=1.25)$. In women with Crohn's disease, once the disease activity is under control, the reproductive health and ovarian reserve do not substantially differ from healthy controls.

\section{Key words}

Crohn's disease • Ovarian reserve • Follicle depletion • AntiMullerian hormone $\bullet$ Reproductive health

\section{Corresponding author}

Tomáš Koller, Gastroenterology, and hepatology Subdiv., $5^{\text {th }}$ Department of Internal Medicine, Comenius University Faculty of Medicine, University Hospital Bratislava, Ružinovská 6, 82606 Bratislava, Slovakia. E-mail: tomas.koller@fmed.uniba.sk

\section{Introduction}

Inflammatory bowel disease (IBD) is a chronic condition affecting the gastrointestinal tract. Its peak prevalence occurs in young individuals during their best reproductive years. It has been reported that women with Crohn's disease (CD) tend to have fewer children than their healthy counterparts (Duricová et al. 2021). The principal reason for the observation was attributed to fear (Ellul et al. 2016; Tavernier et al. 2013). It has been confirmed that patients with inactive $C D$ do not have a higher risk of adverse pregnancy outcomes or congenital abnormalities. However, in active CD, systemic inflammation and local inflammatory lesions in proximity to the female reproductive organs have been implicated in reduced fertility (Kane 2012). Nowadays, due to effective treatment and modern surgical techniques, the disease is kept in remission in the majority of patients (Torres et al. 2019). However, it is still unclear whether repeated disease flares, long-term therapy, and/or surgery affect the ovarian reserve, which reflects the quantity of remaining ovarian follicles (Fleming et al. 2012). The anti-Mullerian hormone has been introduced as a marker of ovarian reserve (OR) with the advantage of being independent of the menstrual 
cycle (Jacobs et al. 2019). Some previous studies have reported conflicting results with AMH levels lower or not different between CD patients and controls (Fréour et al. 2012, Şenateş et al. 2013). Therefore, we aimed to compare parameters of reproductive health and levels of $\mathrm{AMH}$ in patients with Crohn's disease with healthy controls and to explore the effect of disease phenotype on AMH.

\section{Methods}

Patients from two IBD centers over one year (2016) with confirmed Crohn's disease have been recruited to the study. Inclusion criteria for the CD group were: confirmed Crohn's disease by clinical, endoscopic, and/or imaging modalities, age $<45$ years, and signed informed consent form. The control group consisted of age and BMI-matched healthy individuals without a history of assisted reproduction and was recruited from the health care professionals. Patients and controls filled a questionnaire focused on their reproductive health with the following parameters: number of deliveries, age at menarche, history of the irregular menstrual cycle, hirsutism, preterm delivery, spontaneous or induced abortion, previous at-risk pregnancies, history of gynecological surgeries, and current intake of hormonal contraception. Blood samples for inflammatory markers and the anti-Mullerian hormone were drawn at a fasting state to an EDT/gel tube, centrifuged immediately afterward, and frozen at $-20{ }^{\circ} \mathrm{C}$. We used the Elecsys $\mathrm{AMH}$ plus Immunoassay by Roche and AMH concentration is given in ug/l. Although there is no consensus on normal $\mathrm{AMH}$ values, we used AMH cut-offs identified by our local laboratory, where the optimal ovarian reserve was defined as $\mathrm{AMH}>2.27$, and insufficient ovarian reserve as $\mathrm{AMH}<0.68 \mathrm{ug} / \mathrm{l}$. Besides, we have adopted the threshold for low ovarian reserve $(\mathrm{AMH}<1.77 \mathrm{ug} / \mathrm{l})$ validated for the prediction of low antral follicle count by the recent multicenter study using the identical assay (Jacobs et al. 2019).

From the Crohn's disease phenotype, we recorded: age at diagnosis, disease duration, weight (in $\mathrm{kg}$ ), body mass index (BMI, $\mathrm{kg} / \mathrm{m} 2$ ), waist circumference $(\mathrm{cm})$, smoking status, and regular sports activities. Disease phenotype was coded according to Vienna classification (Age: A1-3, Localization L1-3, and Behavior B1-3). Disease activity was evaluated by the established tools: the Harvey-Bradshaw index (HBI), the $\mathrm{C}$ reactive protein, white blood cell count, stool calprotectin, and a short version of the quality-of-life questionnaire in IBD (SIBDQ). CD treatment, previous exposure to anti-TNF, and history of IBD surgery have also been recorded.

Results of non-normally distributed data are given as median and $25^{\text {th }}$ to $75^{\text {th }}$ percentile. Comparison of continuous parameters or proportions was carried out using the Mann-Whitney test or chi-square test, respectively. Since AMH concentration was strongly associated with age, we used linear regression to compare the age-related decrease in AMH between $\mathrm{CD}$ and controls, and among various CD subgroups or phenotypes. Differences in the rate of decline were assessed by comparing the slopes of the curves. The association between AMH and disease phenotypes or reproductive parameters was assessed by dividing the $C D$ patients into two groups according to the validated $\mathrm{AMH}$ cut-off $<1.77 \mathrm{ug} / \mathrm{ml}$. In the multivariate logistic regression in $\mathrm{CD}$ patients, we used this threshold as a dependent variable (low ovarian reserve) and age, disease location, duration, and previous surgery as independent variables. The statistical analysis was carried out using MedCalc Software Ltd. v.19, Ostend, Belgium.

Data acquisition was approved by the local ethics committee of the University Hospital Bratislava Ruzinov. All procedures were carried out following the declaration of Helsinki and later amendments.

\section{Results}

We enrolled $50 \mathrm{CD}$ patients and 56 controls. The median age in controls and CD patients was 31.5 vs. 30.5 years, respectively, and did not differ between the groups. CD patients had lower BMI (20.6 vs. $21.5 \mathrm{~kg} / \mathrm{m}^{2}$, $\mathrm{p}=0.04)$, higher proportion of smokers ( 32.7 vs. $10 \%$, $\mathrm{p}=0.006)$ and a lower proportion of patients practicing regular physical exercise (20 vs. $49 \%, \mathrm{p}=0.002)$. A comparison of baseline characteristics between the groups is displayed in Table 1 .

Among CD patients, $38 \%$ had disease duration equal to or lower than 5 years. The fistulizing disease was present in $18 \%, 60 \%$ were currently treated with an antiTNF antagonist, $72.3 \%$ were previously exposed to this treatment, and $40 \%$ underwent IBD surgery. Overall, the disease activity was low with the median HBI of 1 (IQR 0-3) and stool calprotectin of $66.5 \mathrm{ug} / 1$ (19-177).

The comparison of parameters of reproductive health between CD patients and controls is displayed in Table 2. Although CD patients had a lower proportion of previous spontaneous abortions, at-risk pregnancies, and a higher proportion of induced abortion, the difference 
did not reach statistical significance. The median AMH did not differ between the groups (2.6 vs. $2.1 \mathrm{ug} / \mathrm{l}$, $\mathrm{p}=0.98$ ), neither the proportion of insufficient $\mathrm{AMH}$ (12 vs. $16.1 \%, \mathrm{p}=0.55$ ) or optimal AMH (54 vs. $48 \%$, $\mathrm{p}=0.55)$. The proportion of patients with low ovarian reserve $(\mathrm{AMH}<1.77)$ did not differ between the groups (38 vs. $41.1 \%, \mathrm{p}=0.84$ ).

Table 1. Summary statistics and characteristics of Crohn's disease (CD) patients and controls

\begin{tabular}{|c|c|c|c|}
\hline & $\begin{array}{c}\text { controls, } n=56 \\
\text { median }[25-75 \mathrm{P}] \mathrm{n}(\%)\end{array}$ & $\begin{array}{c}\text { CD, } n=50 \\
\text { median }[25-75 P] \text { n }(\%)\end{array}$ & $\mathbf{P}^{\mathbf{a}}$ \\
\hline Age, years & $31.5[27-40]$ & $30.5[27-38]$ & 0.623 \\
\hline Age at diagnosis & & 23 [19-28] & \\
\hline Disease duration & & $8[4-12]$ & \\
\hline$C D$ duration $\leq 5$ years, $n$ & & $19(38)$ & \\
\hline \multicolumn{4}{|l|}{$(\%)$} \\
\hline Weight, $\mathrm{kg}$ & $62[55-72]$ & $57[52-65]$ & 0.015 \\
\hline Body mass index, $\mathrm{kg} / \mathrm{m}^{2}$ & $21.5[20.1-25.9]$ & $20.6[19.2-23.5]$ & 0.043 \\
\hline Waist circumference, $\mathrm{cm}$ & $75.5[70-83]$ & $71.0[68-82]$ & 0.186 \\
\hline Smoking, $n(\%)$ & $5(10)$ & $16(32.7)$ & 0.007 \\
\hline Sports activities, $n(\%)$ & $25(49)$ & $10(20)$ & 0.002 \\
\hline \multicolumn{4}{|l|}{ Disease classification* } \\
\hline$A 1, n(\%)$ & & $6(12)$ & \\
\hline$A 2, n(\%)$ & & $44(88)$ & \\
\hline$L 1, n(\%)$ & & $24(48)$ & \\
\hline$L 2, n(\%)$ & & $9(18)$ & \\
\hline$L 3, n(\%)$ & & $17(34)$ & \\
\hline \multicolumn{4}{|l|}{ Disease phenotype } \\
\hline$B 1, n(\%)$ & & $27(54)$ & \\
\hline$B 2, n(\%)$ & & $14(28)$ & \\
\hline$B 3, n(\%)$ & & $9(18)$ & \\
\hline \multicolumn{4}{|l|}{ Disease activity } \\
\hline Quality of life score & & $61[51-67]$ & \\
\hline \multicolumn{4}{|l|}{$(S I B D Q)$} \\
\hline Harvey-Bradshaw index & & $1[0-3]$ & \\
\hline Stool calprotectin & & $66.5[19-177]$ & \\
\hline$C$ reactive protein, $m g / l$ & & $2[0.8-6.3]$ & \\
\hline White blood cells, $(* 10.9 / l)$ & & $7.7[0.8-6.3]$ & \\
\hline \multicolumn{4}{|l|}{ Treatment } \\
\hline Steroids, $n(\%)$ & & $2(4)$ & \\
\hline Aminosalicylates, $n(\%)$ & & $30(60)$ & \\
\hline Azathioprine, $\%$ & & $29(28)$ & \\
\hline Anti-TNF alpha, $\%$ & & $30(60)$ & \\
\hline Anti-TNF alpha ever, $\%$ & & $34(72.3)$ & \\
\hline Previous IBD surgery, \% & & $20(40)$ & \\
\hline
\end{tabular}

*Vienna classification: Age of onset: A1<40, A2 $\geq 40$. Localisation: L1 terminal ileum, L2 colon, L3 ileocolonic, Behavior: B1 inflammatory, B2 stricturizing, B3 penetrating

A comparison of Crohn's disease phenotype, the current treatment, and reproductive health parameters according to the AMH cut-off is displayed in Table 3. Patients with low ovarian reserve were significantly older 
(39 vs. 29 years) and their CD started at higher age (27 vs. 22 years), but the disease duration did not differ between the groups. Patients with low ovarian reserve also had a higher proportion of colonic disease (31.6 vs.
$9.7 \%$ ), but the difference did not reach the statistical significance $(p=0.067)$. Otherwise, the two groups did not differ in terms of disease phenotype or treatment.

Table 2. Summary of the reproductive health parameters in women with Crohn's disease (CD) and the controls

\begin{tabular}{lccc}
\hline & $\begin{array}{c}\text { controls, } \mathbf{n}=\mathbf{5 6} \\
\text { median [25-75P] n (\%) }\end{array}$ & $\begin{array}{c}\text { CD, } \mathbf{n}=\mathbf{5 0} \\
\text { median [25-75P] n (\%) }\end{array}$ & $\mathbf{P}^{\mathbf{a}}$ \\
\hline Age at menarche, years & $13.0[12-14]$ & $13.0[12-14]$ & 0.18 \\
Irregular menstrual cycle, $n(\%)$ & $18(33.3)$ & $14(29.2)$ & 0.65 \\
Hirsutism, $n(\%)$ & $6(11.1)$ & $4(8.7)$ & 0.68 \\
Hormonal contraception, $n(\%)$ & $8(14.8)$ & $7(14.6)$ & 0.97 \\
Spontaneous abortion, $n(\%)$ & $5(10)$ & $3(6.8)$ & 0.58 \\
Induced abortion, $n(\%)$ & $3(6)$ & $6(13.6)$ & 0.21 \\
Previous at risk pregnancies, $n(\%)$ & $6(18.8)$ & $3(8.3)$ & 0.21 \\
Preterm labour, $n(\%)$ & $2(6.5)$ & $3(8.6)$ & 0.75 \\
Number of deliveries & $1.0[0-2]$ & $1.0[0-1]$ & 0.56 \\
History of gynecological surgery, $n(\%)$ & $8(15.1)$ & $11(23.4)$ & 0.29 \\
Anti-Mullerian hormone (AMH), ug/l & $2.1[1.2-4.6]$ & $2.61[1.1-4.15]$ & 0.98 \\
Insufficient AMH (<0.68), $n(\%)$ & $9(16.1)$ & $6(12)$ & 0.548 \\
Optimal AMH (>2.27), $n(\%)$ & $27(48.2)$ & $27(54)$ & 0.552 \\
Low ovarian reserve (<1.77), $n(\%)$ & $23(41.1)$ & $19(38)$ & 0.843 \\
\hline
\end{tabular}

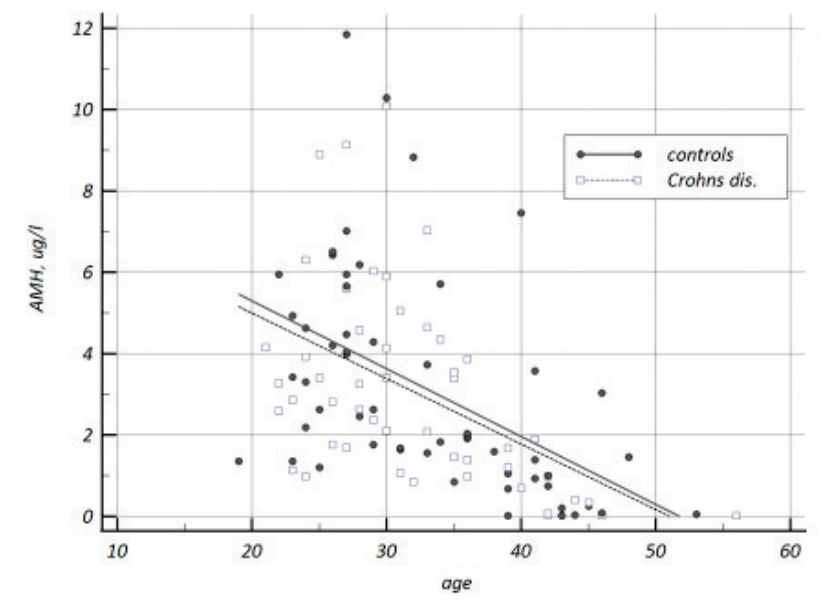

Fig. 1. Age related decrease in anti-Mullerian hormone concentration in Crohn's disease patients (slope $-0.167 \pm 0.04$ ) and controls $(-0.161 \pm 0.04)$, slope difference $-0.006, p=0.92$

The slope of age-related decline of AMH did not differ between CD patients and controls (Fig. 1). By comparing the slope of age-dependent decline in $\mathrm{AMH}$ between CD patients with colonic (L2) and non-colonic (L1, L3) disease, we observed a steeper decline in patients with the colonic disease, but the difference did not reach statistical significance (Fig. 2, left pane). By comparing the slope of decline in $\mathrm{AMH}$ between patients with a penetrating disease with those with a nonpenetrating disease, we did not observe any difference (Fig. 2, right pane). By comparing the slope of decline in $\mathrm{AMH}$ between patients treated with anti-TNF, with those never exposed to anti-TNF, we did not find any difference (Fig. 3, left pane). By comparing the slope of decline in AMH between patients with previous IBD surgery with those who never had IBD surgery, we observed a significantly steeper decline in patients with previous surgery (Fig. 3, right pane). Finally, the slope of AMH decline was not different between patients with disease duration up to five years compared to those exceeding five years (Fig. 4, left pane). However, in patients older than 30 years in whom the disease duration exceeded 5 years, the decline was steeper compared to those with shorter disease duration (Fig. 4, right pane).

In the multivariate analysis, age was the single independently associated factor of predicted low ovarian reserve $(\mathrm{AMH}<1.77 \mathrm{ug} / \mathrm{l}, \mathrm{OR}=1.25$ (95\% CI 1.09-1.43 $\mathrm{p}=0.001)$, but not the colonic location $(\mathrm{OR}=2.15$, $0.33-14.0)$, previous IBD surgery $(\mathrm{OR}=0.71,0.16-3.17$ ) and disease duration shorter than 5 years $(\mathrm{OR}=1.19$, 0.25-5.69). 
Table 3. Characteristics of Crohn's disease (CD) and fertility parameters according to AMH

\begin{tabular}{|c|c|c|c|}
\hline & $\begin{array}{c}\mathrm{AMH} \geq 1.77 \mathrm{ug} / \mathrm{l} \\
\mathrm{n}=31\end{array}$ & AMH $<1.77$ ug/l, n=19 & $P$ value \\
\hline \multicolumn{4}{|c|}{ median $[25-75 \mathrm{P}]$ or $\mathrm{n}(\%)$} \\
\hline Age, $y$ & $29.00[25.50,32.00]$ & $39.00[33.50,42.00]$ & $<0.001$ \\
\hline Body mass index, $\mathrm{kg} / \mathrm{m}^{2}$ & $20.20[19.00,21.62]$ & $21.62[20.47,23.14]$ & 0.122 \\
\hline Smoking, $n(\%)$ & $9(29.0)$ & $7(38.9)$ & 0.537 \\
\hline Age of $C D d g, y$ & $22.00[17.50,25.00]$ & $27.00[24.00,31.00]$ & 0.002 \\
\hline CD duration, $y$ & $8.00[4.00,11.00]$ & $10.00[4.50,14.00]$ & 0.217 \\
\hline$C D$ dg. $<5$ years, $n(\%)$ & $13(41.9)$ & $6(31.6)$ & 0.556 \\
\hline \multicolumn{4}{|l|}{ CD phenotype* } \\
\hline$B 1, n(\%)$ & $17(54.8)$ & $10(52.6)$ & 1.000 \\
\hline$B 2, n(\%)$ & $10(32.3)$ & $4(21.1)$ & 0.522 \\
\hline$B 3, n(\%)$ & $4(12.9)$ & $5(26.3)$ & 0.273 \\
\hline$L 1, n(\%)$ & $17(54.8)$ & $7(36.8)$ & 0.255 \\
\hline$L 2, n(\%)$ & $3(9.7)$ & $6(31.6)$ & 0.067 \\
\hline$L 3, n(\%)$ & $11(35.5)$ & $6(31.6)$ & 1.000 \\
\hline Serum creatinine, umol/l & $56.30[50.70,61.00]$ & $62.10[56.05,65.70]$ & 0.089 \\
\hline \multicolumn{4}{|l|}{ Disease activity } \\
\hline Quality of life score (SIBDQ) & $59.00[46.00,67.00]$ & $64.00[52.75,67.50]$ & 0.398 \\
\hline Harvey-Bradshaw index & $2.00[0.00,4.50]$ & $0.00[0.00,2.00]$ & 0.115 \\
\hline Stool calprotectin, ug/g & $69.10[43.23,190.25]$ & $64.00[15.25,153.00]$ & 0.424 \\
\hline$C$-reactive protein, $\mathrm{mg} / \mathrm{l}$ & $2.08[0.92,7.95]$ & $2.00[0.38,2.80]$ & 0.232 \\
\hline White blood cells, x10.9/l & $7.84[5.97,9.56]$ & $6.91[5.72,8.82]$ & 0.602 \\
\hline Therapy & $2(6.7)$ & $0(0.0)$ & \\
\hline steroids, $n(\%)$ & $2(6.7)$ & $0(0.0)$ & 0.528 \\
\hline aminosalicylates, $n(\%)$ & $18(58.1)$ & $12(63.2)$ & 0.774 \\
\hline azathioprine, $n(\%)$ & $19(61.3)$ & $10(52.6)$ & 0.570 \\
\hline anti-TNF alpha, $n(\%)$ & $18(58.1)$ & $12(63.2)$ & 0.774 \\
\hline anti-TNF alpha ever, $n(\%)$ & $22(73.3)$ & $12(70.6)$ & 1.000 \\
\hline IBD surgery, $n(\%)$ & $12(38.7)$ & $8(42.1)$ & 1.000 \\
\hline \multicolumn{4}{|l|}{ Reproductive health } \\
\hline $\begin{array}{l}\text { Irregular menstrual cycle, } \\
n(\%)\end{array}$ & $10(32.3)$ & $4(23.5)$ & 0.741 \\
\hline Hirsutism, $n(\%)$ & $2(6.9)$ & $2(11.8)$ & 0.619 \\
\hline Spontaneous abortion, $n(\%)$ & $0(0.0)$ & $3(16.7)$ & 0.062 \\
\hline At-risk pregnancy, $n(\%)$ & $0(0.0)$ & $3(17.6)$ & 0.095 \\
\hline Preterm delivery, $n(\%)$ & $1(5.6)$ & $2(11.8)$ & 0.603 \\
\hline Induced abortion, $n(\%)$ & $2(7.7)$ & $4(22.2)$ & 0.208 \\
\hline Deliveries, $n$ & $0.00[0.00,1.00]$ & $1.00[1.00,1.50]$ & 0.016 \\
\hline $0, n(\%)$ & $18(58.1)$ & $4(21.1)$ & 0.043 \\
\hline $1, n(\%)$ & $9(29.0)$ & $10(52.6)$ & \\
\hline $2, n(\%)$ & $4(12.9)$ & $5(26.3)$ & \\
\hline Gynecological surgery, $n(\%)$ & $5(17.2)$ & $6(33.3)$ & 0.291 \\
\hline Contraception, $n(\%)$ & $6(19.4)$ & $1(5.9)$ & 0.396 \\
\hline In-vitro fertilization, $n(\%)$ & $0(0.0)$ & $0(0.0)$ & 1.000 \\
\hline
\end{tabular}

*Vienna classification: Localisation: L1 terminal ileum, L2 colon, L3 ileocolon, Behavior: B1 inflammatory, B2 stricturizing, B3 penetrating 

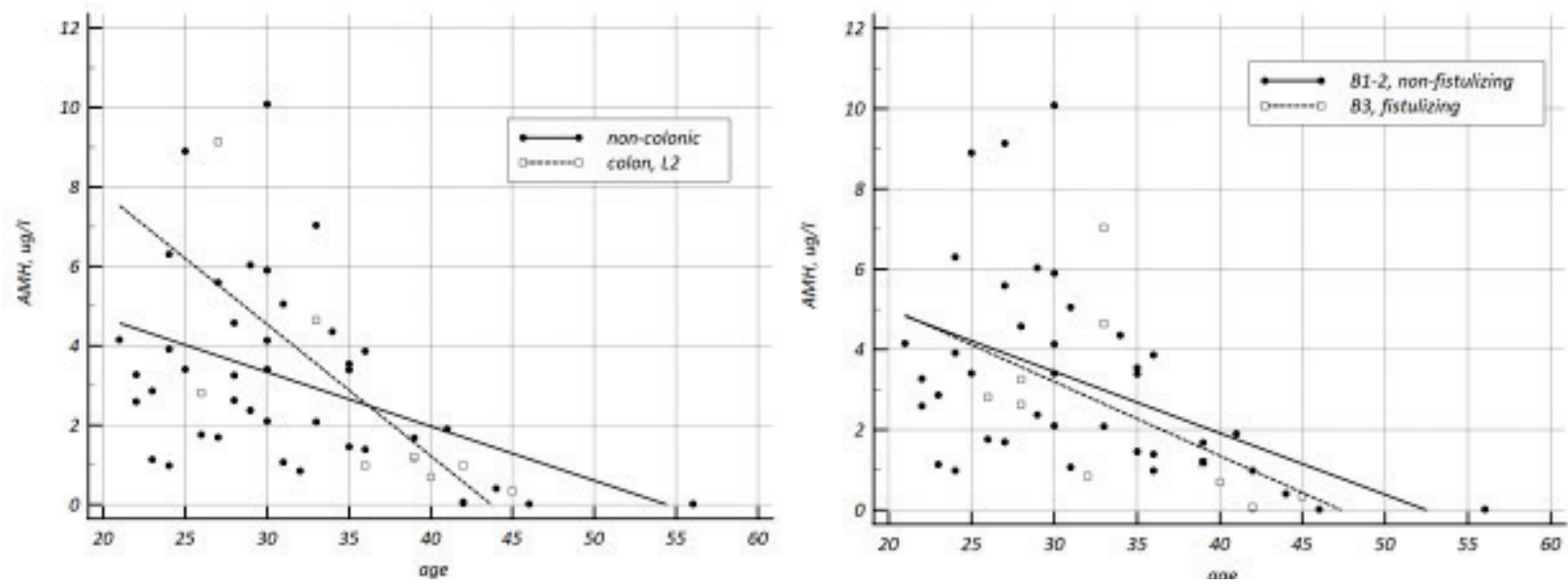

Fig. 2. Age-related decrease in anti-Mullerian hormone concentration according to Crohn's disease behavior. Left pane: non-colonic disease (solid line, slope $-0.137 \pm 0.05$ ) vs. colonic disease (dotted line, slope $-0.331 \pm 0.011$ ), slope difference $-0.195 \pm 0.123, p=0.12$. Right pane: non-fistulizing disease (solid line, slope $0.153 \pm 0.05$ ) vs. fistulizing disease (dotted line, slope $-0.184 \pm 0.1$ ), slope difference $0.031 \pm 0.12, p=0.795$.
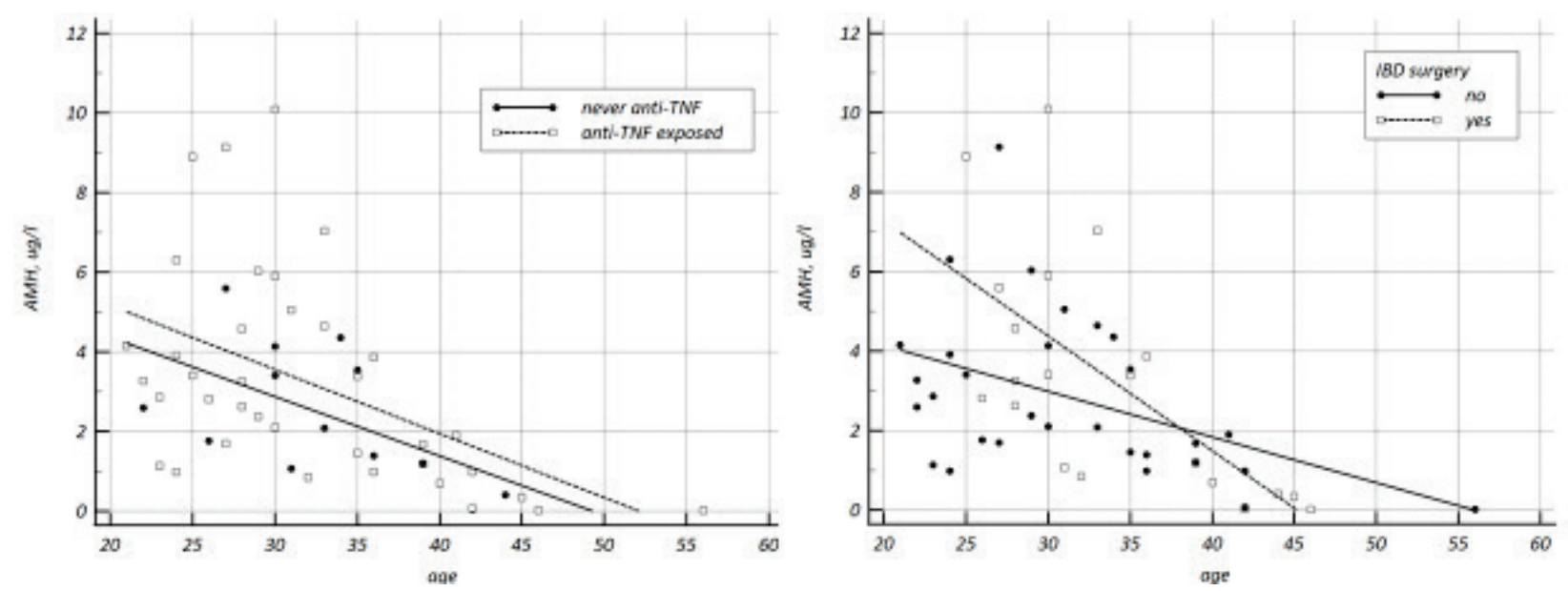

Fig. 3. Age-related decrease in $A M H$ according to previous therapy. Left pane: never exposed to anti-TNF (solid line, slope $0.149 \pm 0.07$ ) vs. exposed to anti-TNF (dotted line, slope $-0.161 \pm 0.05$ ), slope difference $0.012 \pm 0.11, p=0.912$. Right pane: no surgery (solid line, slope $-0.115 \pm 0.04$ ) vs. previous IBD surgery (dotted line, slope $-0.289 \pm 0.08$ ), slope difference $0.174 \pm 0.08, p=0.044$.
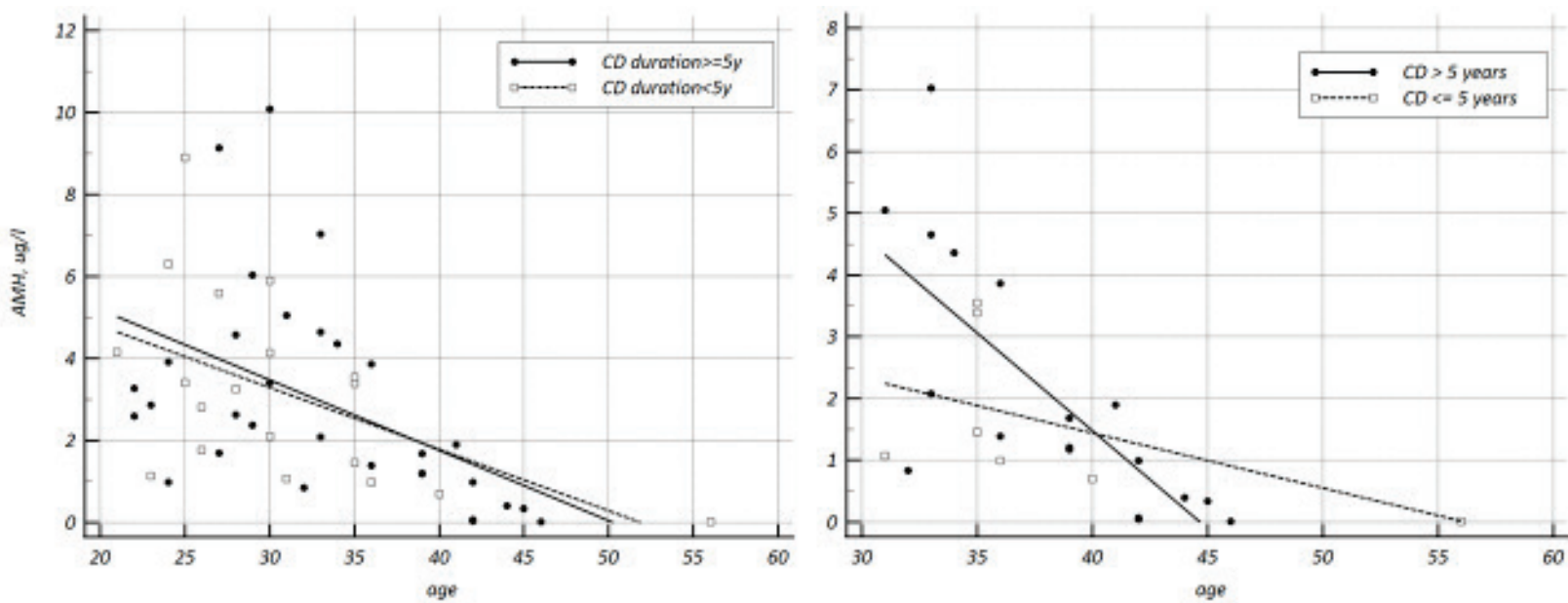

Fig. 4. Age related decrease in AMH according to Crohn's disease duration. Left pane: $\geq 5$ years (solid line, slope $-0.172 \pm 0.06$ ) vs. $<5$ years (dotted line, slope $-0.15 \pm 0.06$ ), slope difference $-0.021 \pm 0.084, p=0.8$ ), Right pane: only individuals older than 30 years, disease duration $>5$ years (solid line, slope $-0.317 \pm 0.07$ ) vs. disease duration $<=5$ years (dotted line, slope $-0.09 \pm 0.06$ ), slope difference $-0.228 \pm 0.1, p=0.03$. 


\section{Discussion}

In our study cohort, we found evidence that parameters of reproductive health, such as previous pregnancy complications and outcomes, did not differ between $\mathrm{CD}$ patients and controls. Besides, the predicted ovarian reserve assessed by $\mathrm{AMH}$ and its rate of agerelated decline did not differ between the groups. AMH levels were not affected by the fistulizing phenotype, nor an exposure or treatment with anti-TNFs. We identified two subgroups of CD patients in whom AMH declined faster with age: patients with previous IBD surgery and patients older than 30 years with disease duration equal or superior to 5 years. In a multivariate analysis, age was the single independent factor predicting the low ovarian reserve.

The ovarian reserve assessed by the AMH in patients with $\mathrm{CD}$ has been previously reported. In the first study, Freour et al. (2012) have studied $50 \mathrm{CD}$ patients in clinical remission and 163 controls recruited among patients with normal ovarian status according to basal and dynamic evaluations after human chorionic gonadotropin administration. The authors observed a strong age-related decline in both groups. Although the slope of $\mathrm{AMH}$ decline was more pronounced in $\mathrm{CD}$ patients, the difference was not statistically significant. Using an $\mathrm{AMH}$ assay (Immunotech Beckman Coulter), the mean AMH levels $(3.12 \pm 1.2$ vs. $3.12 \pm 1.7)$ were similar to our cohort (3.19 \pm 2.6 vs. $3.03 \pm 2.4)$. They also reported a higher proportion of smokers among CD patients $(62 \%$ vs. $32 \%$ ). AMH levels in $\mathrm{CD}$ patients older than 30 years were lower than in controls $(2.2$ vs. $2.97, \mathrm{p}<0.05)$. The authors also defined a condition of "high-risk of altered ovarian reserve" according to the cut-off value of AMH inferior to $2 \mathrm{ug} / \mathrm{l}$. Among CD patients with low $\mathrm{AMH}$, they found a higher proportion of patients with colonic disease ( 45.8 vs. $12.0 \%, \mathrm{p}=0.01$ ) and a trend towards a lower proportion of ileocolic disease (50 vs. $76 \%$, $\mathrm{p}=0.06$ ). Between the groups, they did not observe any difference in proportions of patients with smoking status, previous intestinal resection, or various treatment regimen. In the multivariate model, the colonic disease was independently associated with the high risk of decreased ovarian reserve. In the second study, Senates et al. (Şenateş et al. 2013) have included $35 \mathrm{CD}$ patients and 35 age and BMI-matched controls. The authors used a different assay (ACTIVE MIS/AMH ELISA) and found that $\mathrm{CD}$ patients had a significantly lower $\mathrm{AMH}$ than controls $(1.02 \pm 0.72$ vs. $1.89 \pm 1.8 \mathrm{ng} / \mathrm{ml})$. However, in this study, $43 \%$ of patients had an active disease in whom AMH levels were significantly lower than in patients who were in remission $(0.33 \pm 0.25$ vs. $1.53 \pm 0.48, \mathrm{p}<0.001)$. $\mathrm{AMH}$ levels strongly negatively correlated with the disease activity index CDAI ( $\mathrm{r}=-0.718)$. The authors did not observe a difference in $\mathrm{AMH}$ according to disease duration of more than 5 years $(1.07 \pm 0.79$ vs. $0.97 \pm$ $0.67 \mathrm{ng} / \mathrm{ml}$ ). Patients who underwent surgery had lower $\mathrm{AMH}$, but the difference did not reach statistical significance $(1.33 \pm 0.49$ vs. $0.95 \pm 0.95, \mathrm{p}=0.2)$. In the third and most recent study, (Zhao et al. 2020) authors have enrolled $87 \mathrm{CD}$ patients and 87 age-matched controls with a mean age of 30 years. The authors used an ELISA assay (AMH Gen II) and reported lower mean $\mathrm{AMH}$ levels in $\mathrm{CD}$ patients $(2.47 \pm 2.08 \mathrm{ng} / \mathrm{ml})$ than controls $(3.87 \pm 1.96, \mathrm{p}<0.001)$. However, in patients younger than 25 years, AMH levels did not differ between the groups. Following the previous study, patients with active disease (49\%) had significantly lower AMH levels than patients in remission $(1.34 \pm 1.39$ vs. $3.52 \pm 2.09, \mathrm{p}<0.001)$. For the definition of low ovarian reserve, they used an AMH cutoff of $\leq 1.1 \mathrm{ng} / \mathrm{ml}$. In a univariate model, the following factors were associated with low AMH: age, IBD surgery, structuring phenotype, perianal disease, active disease, and thalidomide therapy. In the multivariate model, age $>25$ years $(\mathrm{OR}=15.3)$, active disease $(\mathrm{OR}=36.3)$, and thalidomide $(\mathrm{OR}=38.2)$ were independently associated with low ovarian reserve.

Our study thus provides complementary evidence to the previous ones. We did not find firm evidence for an overall reduced reproductive potential or lower ovarian reserve in quiescent $C D$. Although our findings could sound reassuring, they need to be interpreted with caution. In all the studies, the risk of reduced ovarian reserve was resonating in some subgroups of CD patients. Also, a relatively low number of patients in all studies did not allow sufficient statistical power and could have underestimated the true risk. First, age was an inherent biological driver of follicle depletion and without age, AMH values cannot be interpreted. Patients with longer disease duration are inherently older, but the cut-off of 25-30 years might represent a tipping point for accelerated follicle depletion. Second, although we have known for some time that IBD surgery might be a risk factor for infertility (van der Woude et al. 2015), recent evidence is far from conclusive (Lee et al. 2019). Surgery is a vastly heterogeneous intervention with substantial individual variation in the extent of operative field and organ involvement, which are factors that the 
current methodology cannot capture. Our study also provides a possible explanation for one of the mechanisms by which surgery might decrease the chance of fertility suggesting, that an intervention in the proximity of the ovaries might hasten follicle depletion. Larger cohorts are needed to establish a firm conclusion on the true effect of IBD surgery on fertility. Although not confirmed by our study, in previous studies the active disease was a substantial driver of decreased AMH. From the studies, it is not clear whether AMH in active disease remains a marker of ovarian reserve, or its decreased levels merely reflect the ongoing inflammation (Kupčová et al. 2003). As a TGF-beta superfamily member, AMH levels might be affected by systemic inflammation. It remains to be explored whether achieving remission might lead to an increase in AMH. Our study also brings more evidence for a trend towards a lower ovarian reserve in patients with the colonic disease. All these remaining issues set the stage for further research or a meta-analysis.

Our study thus supports the critical role of education and counseling of CD patients, which should be aimed at improving the understanding of the mechanisms by which $\mathrm{CD}$ impacts fertility. The current guidelines of the European Crohn's ad Colitis Organisation (ECCO) recommend that appropriate referral to pre-conception counseling is available for all patients with inflammatory bowel disease aiming to facilitate their informed family planning decisions (van der Woude et al. 2015).

Our study is unique in providing a broader look at the fertility parameters in $\mathrm{CD}$ patients. In addition to $\mathrm{AMH}$, our questionnaire included previous pregnancy complications, pregnancy outcomes, and a number of deliveries. Since AMH levels cannot be interpreted without age, we are showing a unique comparison of agerelated decreases between the study groups and various disease phenotypes.

Our study has several limitations. First, the reported fertility rate of 1.0 is lower than the average cumulative fertility rate of 1.6 reported in our country (Šprocha et al. 2019). This observation could be explained by the characteristics of the control group which consisted solely of healthcare professionals, who themselves might differ in fertility parameters from the general population. According to the recent statistical survey, during the last decades, fertility at the of age 31 was far from complete (Šprocha et al. 2019). Second, we attempted to match $\mathrm{CD}$ patients and controls according to BMI. Nevertheless, CD patients had a slightly lower BMI with a possible impact on the fertility parameters. Third, $\mathrm{AMH}$ is only one of the markers of ovarian reserve and there is an ongoing debate on its cut-off levels (Rosenwaks and Reichman 2013). AMH value in isolation cannot be used for individual prediction of fertility success (Rosenwaks and Reichman 2013). Since the majority of studies looking at AMH cut-offs are carried out in the context of assisted reproduction, they might not directly apply to $\mathrm{CD}$ patients. We consider AMH assessment in the context of IBD a research tool, rather than a parameter that should be used in routine clinical practice. AMH in our study was assessed once and the age-related decline was calculated from the entire study population as a function of individual measurements and age. A sequential measurement in all patients could have provided a more precise insight into individual age-related decline. In a real-life practice, patients having difficulties in conceiving should consult a reproductive endocrinologist and/or a center for assisted reproduction.

In summary, our study brings evidence that parameters of reproductive health (previous pregnancy complications and outcomes), and the ovarian reserve (assessed by AMH) in Crohn's disease in remission do not differ from age-matched controls. In patients with previous IBD surgery and those older than 30 years with longer disease duration, we observed the ovarian reserve declining faster with age. However, AMH levels were not affected by the fistulizing phenotype or the treatment with anti-TNFs. In the multivariate analysis, age was the single independent predictor of ovarian reserve. Our report complements data from previous studies and constitutes an important message to $\mathrm{CD}$ patients. Once the disease activity is under control, their reproductive health does not substantially differ from their healthy peers. Finally, in individuals after IBD surgery, or patients older than 25-30 years, longer disease duration, and possibly colonic disease, our findings should serve patients for informed family planning decisions.

\section{Conflict of Interest}

There is no conflict of interest. 


\section{References}

ĎURICOVÁ D, KRÁTKA Z, BORTLIK M, SLABÁ L, STRNADOVÁ K, KOVÁŘOVÁ T, LUKAS M, PFEIFEROVÁ M: Inflammatory bowel disease has a negative impact on patients reproductive behaviour: the first multicentre survey in the Czech Republic. Gastroenterol Hepatol 75: 12-19, 2021. https://doi.org/10.48095/ccgh202112

ELLUL P, ZAMMITA SC, KATSANOS KH, CESARINI M, ALLOCCA M, DANESE S, KARATZAS P, MORENO SC, KOPYLOV U, FIORINO G, TORRES J, LOPEZ-SANROMAN A, CARUANA M, ZAMMIT L, MANTZARIS G: Perception of reproductive health in women with inflammatory bowel disease. J Crohn's Colitis 10: 886-891, 2016. https://doi.org/10.1093/ecco-jce/jjw011

FLEMING R, KELSEY TW, ANDERSON RA, WALLACE WH, NELSON SM: Interpreting human follicular recruitment and antimüllerian hormone concentrations throughout life. Fertil Steril 98: 1097-1102, 2012. https://doi.org/10.1016/j.fertnstert.2012.07.1114

FRÉOUR T, MIOSSEC C, BACH-NGOHOU K, DEJOIE T, FLAMANT M, MAILLARD O, DENIS MG, BARRIERE P, BRULEY DES VARANNES S, BOURREILLE A, MASSON D: Ovarian reserve in young women of reproductive age with Crohn's disease. Inflam Bowel Dis 18: 1515-1522, 2012. https://doi.org/10.1002/ibd.21872

JACOBS MH, REUTER L M, BAKER VL, CRAIG LB, SAKKAS D, SURREY E, DOODY KJ, JUNGHEIM ES, BAYRAK AB, HUND M, VERHAGEN-KAMERBEEK WDJ, PARDUE D, BUCK K, TIMM B: A multicentre evaluation of the Elecsys( $(\mathbb{B})$ anti-Müllerian hormone immunoassay for prediction of antral follicle count. Reprod Biomed Online 38: 845-852, 2019. https://doi.org/10.1016/j.rbmo.2018.12.041

KANE S: Inflammatory Bowel Disease in Pregnancy. In: Pediatric Inflammatory Bowel Disease. P MAMULA (ed), Springer Science+ Bussiness Media, 2012, pp 515-16. https://doi.org/10.1007/978-1-4614-5061-0 47

KUPČOVÁ V, TURECKÝ L, DETKOVÁ Z, PRÍKAZSKÁ M, KELEOVÁ A: Changes in acute phase proteins after anti-tumor necrosis factor antibody (infliximab) treatment in patients with Crohn's disease. Physiol Res 52: 89-93, 2003.

LEE S, CROWE M, SEOW CH, KOTZE PG, KAPLAN GG, METCALFE A, RICCIUTO A, BENCHIMOL EI, KUENZIG ME: The impact of surgical therapies for inflammatory bowel disease on female fertility. Cochrane Database Syst Rev 7: CD012711, 2019. https://doi.org/10.1002/14651858.CD012711.pub2

ROSENWAKS Z, REICHMAN DE: Use of antimüllerian hormone: the risks of interpreting ovarian reserve markers in isolation. Fertil Steril 99: 1850. 2013. https://doi.org/10.1016/j.fertnstert.2013.03.036

ŞENATEŞ E, ÇOLAK Y, ERDEM ED, YEŞIL A, COŞKUNPINAR E, ŞAHIN Ö, ALTUNÖZ ME, TUNCER I, KURDAŞ ÖVÜNÇ AO: Serum anti-Müllerian hormone levels are lower in reproductive-age women with Crohn's disease compared to healthy control women. J Crohns Colitis 7: e29-34, 2013. https://doi.org/10.1016/j.crohns.2012.03.003

ŠPROCHA B, BLEHA B, GARAJOVÁ A, PILINSKÁ V, MÉSZÁROS J, VAŇO B: Population Development in Regions and Districts of Slovakia Since the Beginning of the 21st Century. B ŠPROCHA (ed), INFOSTATInstitute of Informatics and Statistics, Bratislava, 2019, pp. 46.

TAVERNIER N, FUMERY M, PEYRIN-BIROULET L, COLOMBEL JF, GOWER-ROUSSEAU C: Systematic review: fertility in non-surgically treated inflammatory bowel disease. Aliment Pharmacol Ther 38: 847-853, 2013. https://doi.org/10.1111/apt.12478

TORRES J, BONOVAS S, DOHERTY G, KUCHARZIKT, GISBERT JP, RAINET, ADAMINA M, ARMUZZI A, BACHMANN O, BAGER P, BIANCONE L, BOKEMEYER B, BOSSUYT P, BURISCH J, COLLINS P, EL-HUSSUNA A, ELLUL P, FREI-LANTER C, FURFARO F, GINGERT C, GIONCHETTI P, GOMOLLON F, GONZÁLEZ-LORENZO M, GORDON H, HLAVATY T, JUILLERAT P, KATSANOS K, KOPYLOV U, KRUSTINS E, LYTRAS T, MAASER C, MAGRO F, KENNETH MARSHALL J, MYRELID P, PELLINO G, ROSA I, SABINO J, SAVARINO E, SPINELLI A, STASSEN L, UZZAN M, VAVRICKA S, VERSTOCKT B, WARUSAVITARNE J, ZMORA O, FIORINO GIONATA ON BEHALF OF THE ECCO: ECCO Guidelines on Therapeutics in Crohn's Disease: Medical Treatment. J Crohns Colitis 14: 4-22, 2019. https://doi.org/10.1093/ecco-jcc/jijz180 
VAN DER WOUDE CJ, ARDIZZONE S, BENGTSON MB, FIORINO G, FRASER G, KATSANOS K, KOLACEK S, JUILLERAT P, MULDERS AGMGJ, PEDERSEN N, SELINGER C, SEBASTIAN S, STURM A, ZELINKOVA Z, MAGRO F: The second European evidenced-based consensus on reproduction and pregnancy in inflammatory bowel disease. J Crohns Colitis 9: 107-124, 2015. https://doi.org/10.1093/eccojec/jju006

ZHAO Y, CHEN B, HE Y, ZHANG S, QIU Y, FENG R, YANG H, ZENG Z, BEN-HORIN S, CHEN M, MAO R: Risk Factors associated with impaired ovarian reserve in young women of reproductive age with Crohn's Disease. Intest Res 18: 200-209, 2020. https://doi.org/10.5217/ir.2019.00103 